\title{
DYNAMIC AND SPATIAL IMPACT OF HURRICANE ANDREW ON FLORIDA'S TAXABLE SALES: AN INTERVENTION ANALYSIS
}

\author{
David G. Lenze*
}

\begin{abstract}
This paper shows how intervention analysis can be used to estimate the dynamic and spatial impact of recovery from a natural disaster. Specifically, it shows how to estimate three distinct phases of recovery: immediate impact, transitory recovery impact, and negative aftershock. It also discusses the estimation of a permanent impact. The method is then used to estimate the impact on Florida's taxable sales of the recovery from Hurricane Andrew. Estimates are provided of the immediate and total impact in five regions, and the length of the recovery is discussed. The results are compared to earlier impact studies of natural disasters on taxable sales. On the basis of studies of other hurricanes, it is found that the recovery from Hurricane Andrew has taken much longer than might be expected It is also found that, despite the magnitude of the insurance and transfer payments received by victims, the impact on taxable sales was within the normal variation of taxable sales at the state level, but significantly larger at the MSA level.
\end{abstract}

This paper considers whether intervention analysis can be used to estimate the dynamic and spatial impact of a natural disaster on a local economy. Few applications of intervention analysis have been published in the major journals devoted to regional studies (see, for instance, Blackley 1992) and there is as yet no generally accepted methodology for measuring the impacts of natural disasters (West and Lenze 1994). We focus on taxable sales because this series can be easily modeled and comparisons can be readily made to earlier research in the natural disaster field using alternative methods (Chang 1983, Cochrane 1992, 1996, and Bolton and Kimbell 1995). One advantage of intervention analysis is that fewer data requirements are needed than for a simultaneous-equation, structural econometric model. A second advantage is that higher frequency data than are typically used by builders of econometric models can be analyzed; temporal aggregation may obscure the very dynamics one is trying to uncover. A disadvantage is that intervention analysis can determine only whether or not there is an impact. By itself, it is not an economic model of the impact.

Previous work in the field suggests that a natural disaster and the subsequent economic recovery consist of three distinct (perhaps overlapping) phases: (1) a negative immediate impact; (2) a positive, delayed recovery impact; and (3) a negative aftershock (Guimaraes, Hefner, and Woodward 1993, Chang 1983, West

\footnotetext{
*Associate in Research, Bureau of Economic and Business Research, University of Florida. The author wishes to thank Carol T. West, Andrew Krikelas, and David Denslow for helpful comments; however, they are not responsible for any shortcomings of this paper. An earlier version of this paper (with a different title) was presented at the 1996 Southem Regional Science Association Meetings.
} 
and Lenze 1994). These impacts are transitory and result from the spending of compensation from insurance companies and government transfer payments. In addition, there may be permanent impacts due to uninsured property losses (Brookshire and McKee 1992, Cochrane 1995) and population dispersal after the disaster (Smith 1994, Smith and McCarty 1996).

This paper confirms the existence of phases 1 and 2 in the case of Hurricane Andrew in Florida but not the negative aftershock (phase 3). It was not possible to separately estimate the permanent impacts.

\section{THE DATA AND THE DISASTER}

We use nominal, not-seasonally-adjusted taxable sales data from the Florida Department of Revenue. Data tabulated by county from November 1983 through December 1995 were used after adjusting their reference dates so that they refer to the month in which the sales were made, rather than the month in which firms reported the sales to the Department. Earlier data are available, but were not used to avoid complications such as changes in legal tax reporting requirements and the impacts of other exogenous shocks. A review of Florida Trend magazine's annual Economic Yearbook and the Florida Outlook, a quarterly forecasting publication of the University of Florida, confirms our belief that the 1983-95 period is generally free of important exogenous shocks to aggregate taxable sales, with one exception: the sales tax was temporarily extended to services July-December 1987. This was controlled for by methods similar to that described in this paper for Hurricane Andrew. It is not treated at length here because it does not provide any additional insights into either the intervention analysis methodology or the hurricane.

Hurricane Andrew came ashore in the Miami MSA in August 1992 and caused about $\$ 16.0$ billion of insured damage, almost four times as much damage as Hurricane Hugo, the previous record holder. Prior to the hurricane, the Florida economy had just pulled out of the 1990-91 recession and still had a rather large excess supply of multifamily housing. Many macroeconomists were finding the national recovery to be unusually slow (Blanchard 1993). The recession in Miami was especially severe, coinciding with the elimination of a major regional bank and two major airlines.

Though the disaster was primarily concentrated in the Miami MSA, damaging 134,000 dwelling units, the American Red Cross also identified 1,600 damaged units in Monroe County, 1,200 in the Fort Lauderdale MSA, and 900 in the Naples MSA (Figure 1). The unprecedented magnitude of this disaster in South Florida had far-ranging economic repercussions. Mobile home manufac- 
Figure 1

Spatial Dimension of Recovery from Hurricane Andrew

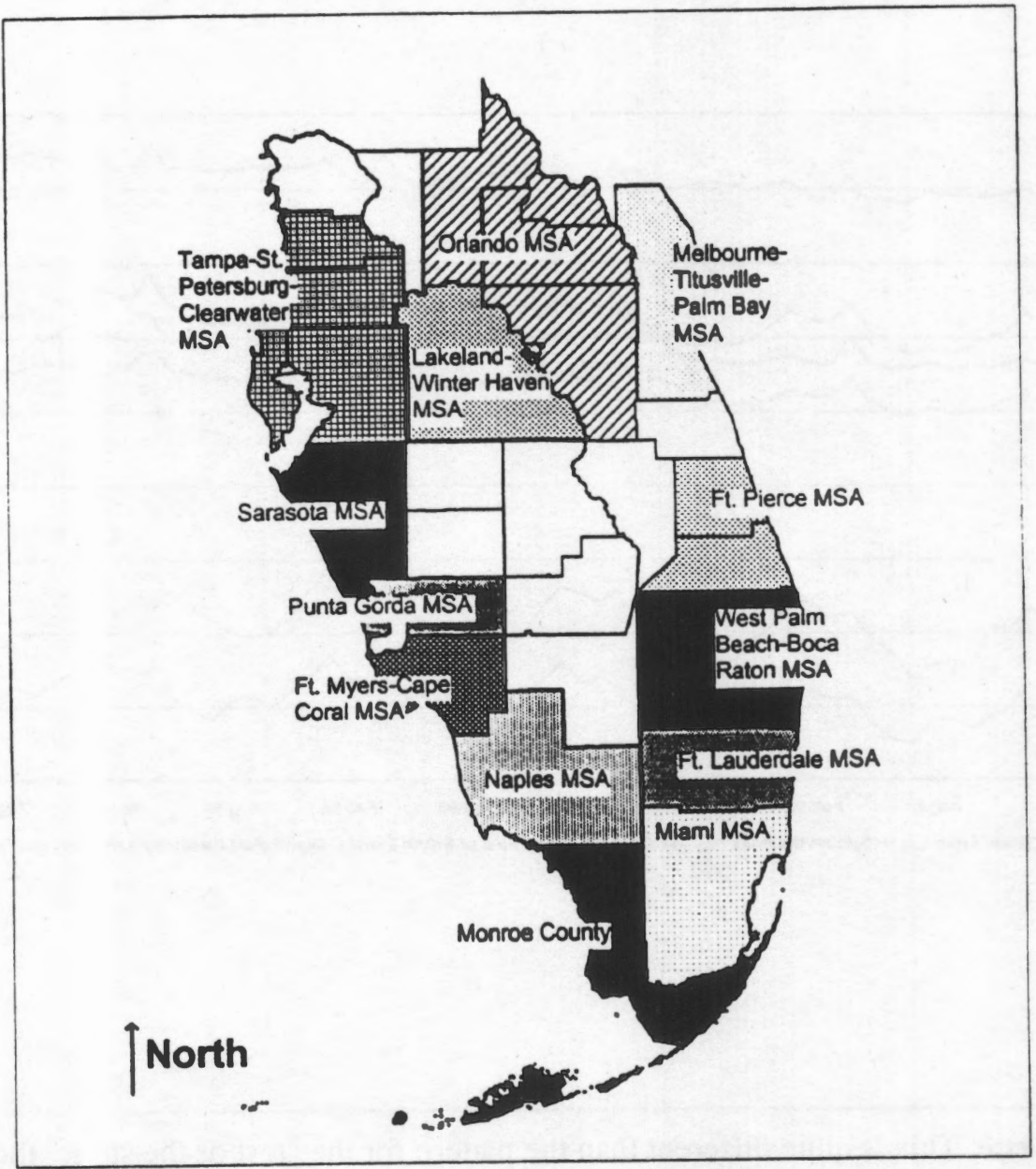

Note: Miami's western boundary is approximately 55 miles long.

turers in central Florida and boat builders and repairers along both of Floridas coasts enjoyed a strong demand for their goods and services. Utility crews, insurance adjustors, construction workers, and federal bureaucrats converged on Miami from northern Florida and around the country.

Figure 2 illustrates several years of taxable sales for six areas of Florida. Notice the sharp dip in Miami's taxable sales in August 1992 and subsequent 
Figure 2

Taxable Sales (natural logarithm)

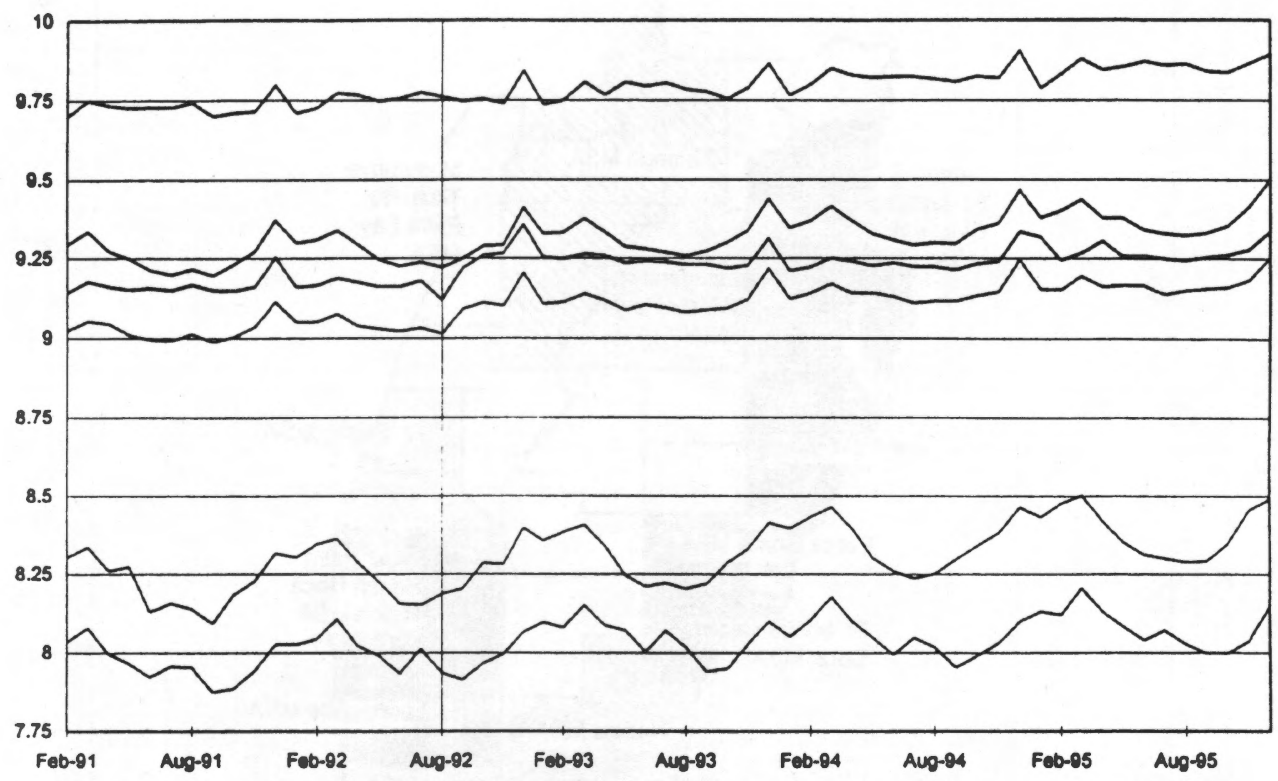

Note: From top to bottom the lines represent Rest of State, Reat of South Florlda, Miaml, Fort Lauderdak, Naples, and Monroe.

sharp rise. This is quite different than the pattern for the "rest of the state," though in other periods, taxable sales for the two areas illustrate remarkable similarity. This figure also illustrates the seasonal pattern of taxable sales, with Christmas and springtime peaks. (Seasonality in Naples and Monroe, where the springtime peak exceeds the Christmas peak, is quite different from Miami and Ft. Lauderdale.)

\section{PRE-DISASTER ARIMA MODELS}

As a preliminary to the intervention analysis, ARIMA models were estimated for Miami, Fort Lauderdale, Naples, Monroe County, the Rest of South Florida (the Fort Pierce, West Palm Beach, Fort Myers, Sarasota, and Punta 
TABLE 1

Taxable Sales ARIMA Models, Pre-Hurricane Andrew

$\begin{array}{lrrrrr}\text { Miami } & \theta_{12} & \phi_{1} & \phi_{2} & \text { SER } & \text { AIC } \\ & 0.5379 & -0.4881 & -0.2629 & 0.0443 & -279 \\ \text { Fort Lauderdale } & (0.1040) & (0.1119) & (0.1118) & & \\ & \theta_{12} & \phi_{1} & \phi_{2} & & \\ & 0.5198 & -0.6210 & -0.2653 & 0.0284 & -355 \\ \text { Monroe } & (0.1139) & (0.1121) & (0.1117) & & \\ & \theta_{12} & \phi_{1} & \phi_{2} & & \\ \text { Naples } & 0.6362 & -0.5785 & -0.2362 & 0.0390 & -301 \\ & (0.0982) & (0.1136) & (0.1158) & & \\ & \theta_{1} & \theta_{12} & \phi_{12} & & \\ \text { Rest of South } & 0.7601 & -0.2505 & -0.4997 & 0.0455 & -275 \\ \text { Florida } & (0.0664) & (0.1016) & (0.1571) & & \\ & \theta_{12} & \phi_{1} & \phi_{2} & & \\ \text { Rest of State } & 0.5129 & -0.5639 & -0.3079 & 0.0287 & -353 \\ & (0.1145) & (0.1123) & (0.1130) & & \\ & \theta_{12} & \phi_{1} & \phi_{2} & & \\ \text { Florida } & 0.2936 & -0.3743 & -0.1589 & 0.0252 & -375 \\ & (0.1238) & (0.1161) & (0.1171) & & \\ & \theta_{12} & \phi_{1} & \phi_{2} & & \\ & 0.3870 & -0.3841 & -0.2355 & 0.0241 & -383 \\ & (0.1208) & (0.1135) & (0.1146) & & \end{array}$

\footnotetext{
Notes: Parameters for the temporary service tax intervention are not reported in this table.

AIC $=$ Akaike Information Criterion

SER $=$ Standard Error of the Regression

Approximate standard errors are in parentheses.

The sample period used is November 1983-December 1991.
}

Gorda MSAs and seven nonmetropolitan counties) and the Rest of the State (all other counties in Florida). An ARIMA model was also estimated for the state as a whole. Estimates are presented in Table 1. The general form of the ARIMA model is given by:

$$
z_{t}=\Delta^{D} \Delta^{d} \ln \left(y_{t}\right)=\frac{\theta(\mathrm{B})}{\phi(\mathrm{B})} a_{t}
$$

where $y$ is taxable sales, $\Delta$ is a difference operator, $\beta$ is a backshift operator, $t$ indexes time, $d$ and $D$ indicate the degree of nonseasonal and seasonal differencing, $\theta(B)$ and $\phi(B)$ are polynomials of degree $q$ and $p$, and $a$ is a white noise variable. Seasonal differencing $(D=12)$, as well as the typical logarithmic first differences 
$(d=1)$, were necessary to obtain stationarity. Equations for all areas except Naples have a single moving-average term with a 12 th order lag, $\theta_{12}$, and two autoregressive terms, $\phi_{1}, \phi_{2}$, Naples has two moving-average terms, $\theta_{1}$, and $\theta_{2}$, and a single autoregressive term, $\phi_{12}{ }^{1}$

\section{INTERVENTION ANALYSIS}

Intervention analysis is one way to examine the response of a time series to an exogenous event (Box and Tiao 1975). It is especially well suited to the study of natural disasters which occur at particular points in time, but which have lingering effects.

In this paper we will use the symbol $\xi_{t}$ for an exogenous event which affects a focus variable, $y_{t}$. In general, $\xi_{t}$ can be any time series variable, but for our purposes it will be useful to think of it as an indicator variable taking a value of 1 and 0 , according to the occurrence and nonoccurrence of the intervention. The dynamic transfer from $\xi_{t}$ to $y_{t}$ will be represented by the symbol $I_{t}$ (for intervention variable). This leads to the following modification of the standard ARIMA model:

$$
\Delta^{d} \Delta D_{t}=I_{t}+\frac{\theta(\mathrm{B})}{\phi(\mathrm{B})} a_{t}
$$

The intervention variable is assumed to be generated by the linear difference equation:

$$
I_{t}=\frac{\omega(\mathrm{B})}{\delta(\mathrm{B})} \xi_{\mathrm{t}}
$$

where $\omega(B)$ and $\delta(B)$ are polynomials of degree $r$ and $s$.

An exogenous event such as a natural disaster which occurs at time $T$ and lasts a single period can be conveniently described by a pulse indicator, i.e. $\xi_{t}=P_{t}(T)$, where

$$
P_{t}^{(T)}= \begin{cases}0 & \mathrm{t} \neq T \\ 1 & \mathrm{t}=T\end{cases}
$$

In order to estimate Eq. (2), some structure must be placed on both the intervention variable and the noise variable. The noise variable has been estimated al- 
Figure 3a

Dynamic Response to an Intervention

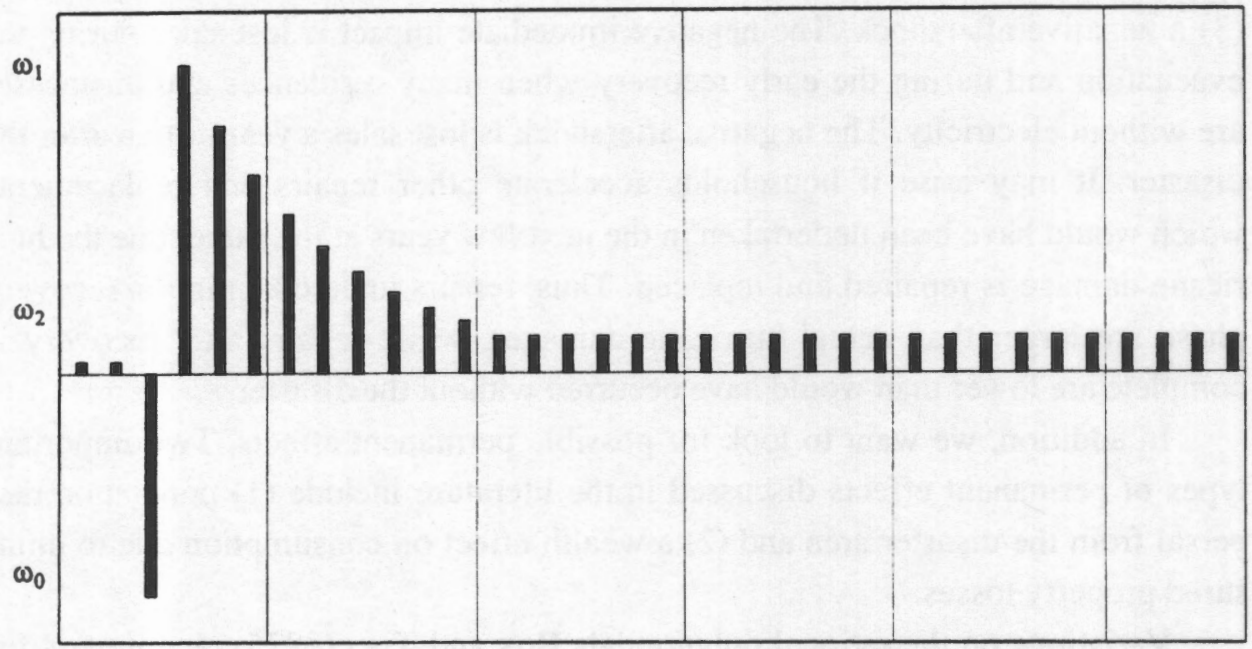

Figure 3b

Dynamic Response to an Intervention With an Aftershock

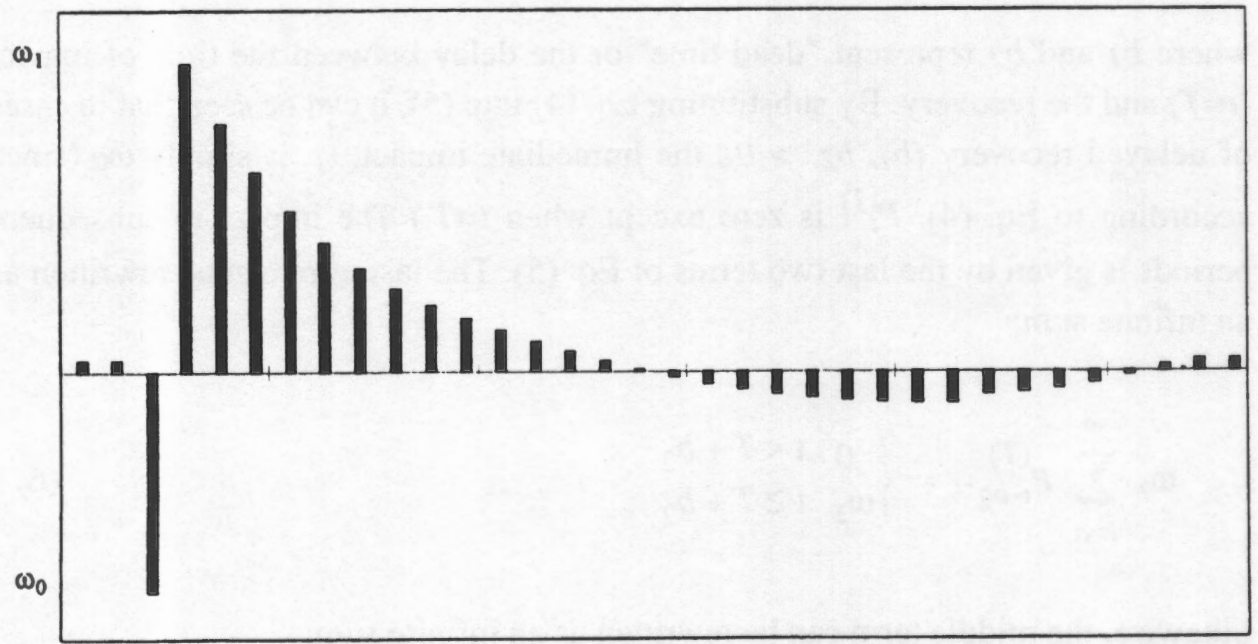


ready in section II; the following comments apply to the structure of the intervention variable.

On the basis of previous empirical work (e.g., Chang 1983, Guimaraes, Hefner, and Woodward 1993, and West and Lenze 1994), we want to look for (1) a negative immediate impact, (2) a positive, delayed recovery impact, and (3) a negative aftershock. The negative immediate impact is lost sales during the evacuation and during the early recovery when many residences and businesses are without electricity. The negative aftershock is lost sales a year or two after the disaster. It may arise if households accelerate other repairs and replacements which would have been undertaken in the next few years at the same time the hurricane damage is repaired and replaced. Thus, repairs undertaken in the recovery phase are larger than actual hurricane damages, while repairs after recovery is complete are lower than would have occurred without the disaster.

In addition, we want to look for possible permanent effects. Two important types of permanent effects discussed in the literature include (1) population dispersal from the disaster area and (2) a wealth effect on consumption due to uninsured property losses.

Variations on the rational polynomials Box and Tiao (1975) recommend for the intervention, $I_{t}$, in Eq. (2) can readily account for these dynamics. If the dynamic response to an intervention is as in Figure 3a (an initial decline followed by a sharp rise which does not entirely dissipate over time), one might want to use a specification as follows:

$$
I_{t}=\omega_{O} P_{t}^{(T)}+\frac{\omega_{1}}{1-\delta \mathrm{B}} P_{t-b 1}^{(T)}+\frac{\omega_{2}}{1-\mathrm{B}} P_{t-b_{2}}^{(T)}, \quad|\delta|<1
$$

where $b_{1}$ and $b_{2}$ represent "dead time" or the delay between the time of impact $(t=T)$ and the recovery. By substituting Eq. (4) into (5), it can be seen that in cases of delayed recovery $\left(b_{1}, b_{2}>0\right)$, the immediate impact, $I_{T}$, is simply $\omega_{0}$ (since according to Eq. (4), $P_{l}^{(T)}$ is zero except when $t=T$.) The impact in subsequent periods is given by the last two terms of Eq. (5). The last term can be rewritten as an infinite sum:

$$
\omega_{2} \sum_{i=0}^{\infty} P_{t-b_{2}-i}^{(T)}=\left\{\begin{array}{rl}
0 & t<T+b_{2} \\
\omega_{2} & t \geq T+b_{2}
\end{array}\right.
$$

Likewise, the middle term can be rewritten as an infinite sum: 


$$
\omega_{1} \sum_{i=0}^{\infty} \delta^{i} P_{t-b_{1}}^{(T)}=\left\{\begin{array}{cc}
0 & t<T+b_{2} \\
\omega_{1} \delta^{i-\left(T+b_{1}\right)} & t \geq T+b_{2}
\end{array}\right.
$$

If $|\delta|<1$, this term approaches 0 as $t \rightarrow \infty_{\text {.. Thus }} \omega_{2}$ can be thought of as the permanent effect and $\omega_{1}$ as the initial value of the transitory recovery response. It is clear that the larger $\delta$, the longer the transitory response persists, becoming permanent when $\delta=1$.

Eq. (5) is quite flexible. A slight alteration will yield a specification that can replicate the type of aftershock illustrated in Figure $3 \mathrm{~b}$. In this illustration, the dynamic response to the intervention falls to zero and becomes slightly negative. This figure was generated from an equation of the form of Eq. (8) (which becomes Eq. (5) when $\delta_{2}=1$ ).

$$
I_{t}=\omega_{0} P_{t}^{(T)}+\frac{\omega_{1}}{1-\delta_{1} \mathrm{~B}} P_{t-b_{1}}^{(T)}+\frac{\omega_{2}}{1-\delta_{2} \mathrm{~B}} P_{t-b_{2}}^{(T)}
$$

Several variations of interventions of the form of Eqs. (5 and 8) were estimated. Highlights from these estimates are presented and discussed next.

\section{ESTIMATES OF THE EFFECT OF HURRICANE ANDREW ON TAXABLE SALES}

Estimates of the best-fitting equations are presented in Table 2. Selection between alternative specifications was on the basis of the Akaike Information Criterion (AIC) as well as the economic sensibility of the estimates. For Miami and Florida the restrictions, $b_{1}=1$ and $b_{2}=2$, were imposed. For Fort Lauderdale, Naples, Monroe, and the rest of south Florida it was found that the restrictions $\omega_{2}=0$ and $b_{1}=1$ fit best, while for the Rest of the State the restrictions $\omega_{0}=0$, $\omega_{2}=0$, and $b_{1}=1$ were used. Thus in all areas (except for the Rest of the State) we estimate an immediate impact. In addition, in Miami and Florida we also estimate transitory and permanent impacts, and transitory impacts in the other areas. The transitory recovery begins in the month after the disaster in all areas.

It is noteworthy that for Miami, Fort Lauderdale, Monroe, and the Rest of South Florida, the parameter estimates are stable. For these areas, most of the estimates of the noise parameters and standard errors of the regressions in Table 2 (using additional observations "contaminated" by the hurricane) are very similar to those presented in Table 1. The Naples model, on the other hand, is unstable, 
with the estimate of $\theta_{12}$ changing sign. This leads to some anomalous results in later analysis.

Miami. In the case of Miami where the fury of the hurricane was greatest, the estimate of the immediate impact parameter $\omega_{0}$, indicates an approximately 12 percent decline in sales in the month of the hurricane, while the estimate of the transitory recovery parameter $\omega_{1}$ indicates a subsequent 14 percent surge. (This compares with a seasonal Christmas surge of about 20 percent.) The estimate of the persistence parameter $\delta$ may appear to be rather high (.87); and in fact it is not significantly different from unity. However, it should be kept in mind that this is a monthly rate. After twelve months the impact will decline to only 19 percent of its original level (ignoring feedbacks) and it falls to less than 4 percent after two years. The estimate of the permanent effect, $\omega_{2}$, is about 10 percent.

How plausible is a permanent 10 percent increase in taxable sales after a hurricane? Smith (1994) and Smith and McCarty (1996) estimated that Hurricane Andrew permanently dispersed about 39,000-70,000 persons from their homes in Miami, with about 12,000-20,000 going to Fort Lauderdale, and the rest either relocating elsewhere in Florida or leaving the state. If sales were proportional to population, this would have a 2.0 to 3.5 percent permanent negative impact on Miami's taxable sales and a 0.9 to 1.5 percent positive impact on Fort Lauderdale's. As a first approximation, these would be our priors for $\omega_{2}$ in Eq. (5).

A second permanent effect is uncompensated property losses, which reduce household wealth and, hence, consumption. Such losses were probably relatively low in the case of Hurricane Andrew, and to some extent they were offset by specially legislated transfer payments from the federal government as well as by federally subsidized loans. The remaining uncompensated losses would tend to lower the value of $\omega_{2}$.

Both of these permanent effects would have a negative impact on taxable sales in Miami, yet we estimate a positive impact. What else might be going on? In addition to measuring permanent impacts of these sorts, $\omega_{2}$ is probably also picking up long-persisting transitory impacts, impacts which dominate the permanent impacts.

Initial expenditure after a disaster is typically dominated by emergency repairs and purchases. These will surge immediately and then fall off sharply. Afterwards, less essential replacements will be made at a slower and steadier pace. Roof repair is an example of the former, pleasure boat repair an example of the latter. Not only does the shortage of supply services dictate such a pace, but also the fact that repair and replacement consumes a substantial amount of household time. 
In addition, although more than 100,000 housing units were damaged or destroyed, there was no surge in housing permits or housing starts after the hurricane. Indeed, many real estate experts before the disaster were bemoaning Miami's excess supply of rental housing. In such a case, investors would not be in any hurry to rebuild every destroyed dwelling, but would rather invest their insurance proceeds in financial instruments (for instance), and only gradually add to the housing stock as the population grew and as the market demanded additional rental housing.

Thus $\omega_{2}$ cannot be identified solely as the permanent impact on taxable sales due to population dispersal and uninsured lost wealth. It also incorporates a slow but fairly steady transitory impact, an impact which we expect will dissipate as time progresses.

Ideally, one would like to estimate an expanded version of Eq. (5) in which there is another term for these transitory but long-persisting impacts. However, until enough time elapses for these impacts to dissipate, the data will not permit the separate estimation of these long-persisting transitory impacts and the negative permanent impacts due to population dispersal and uninsured wealth losses. This remains a challenge for future research.

Another implication of these long-persisting transitory impacts is that they mask the aftershock effect, if any exists.

Fort Lauderdale. Although on a priori grounds, we expected a permanent increase in taxable sales in Fort Lauderdale, an equation without a permanent impact term fit the data better. We estimate the immediate impact in Fort Lauderdale to be about -.3 percent, while the subsequent recovery surge was 16 percent, slightly higher than in Miami. The persistence parameter was estimated to be .86 , about the same as in Miami. The magnitude of the recovery in Fort Lauderdale is quite large, far exceeding its share of hurricane damage. However, because of the proximity of Fort Lauderdale to Miami (Figure 1), the close integration of their economies (the two counties make up one Consolidated Metropolitan Statistical Area), and the dispersion of population from Miami to Fort Lauderdale in the aftermath, the large impact on taxable sales is reasonable.

Other areas. Outside Miami the negative immediate response was greatest in Monroe ( 7 percent). In the Rest of South Florida it was a negligible -0.1 percent. As there is no reason to expect losses in the Rest of the State, the parameter was excluded from its equation.

The transitory recovery response is largest in Naples (12 percent), followed by Monroe ( 6 percent), and the Rest of South Florida ( 5 percent). For the Rest of the State it is estimated to be -0.6 percent, which is both negligible in size and statistically insignificant. It persisted longest in Monroe (estimated to be .96) fol- 
TABLE 2

Taxable Sales, Hurricane Andrew Intervention Models

\begin{tabular}{|c|c|c|c|c|c|c|c|c|c|}
\hline Miami & $\begin{array}{r}\theta_{12} \\
0.5716 \\
(0.0913)\end{array}$ & $\begin{array}{r}\phi_{1} \\
-0.5744 \\
(0.0876)\end{array}$ & $\begin{array}{r}\phi_{2} \\
-0.3727 \\
(0.0877)\end{array}$ & $\begin{array}{r}\omega_{1} \\
0.1358 \\
(0.0379)\end{array}$ & $\begin{array}{r}\delta \\
0.8692 \\
(0.1508)\end{array}$ & $\begin{array}{r}\omega_{0} \\
-0.1152 \\
(0.0374)\end{array}$ & $\begin{array}{r}\omega_{2} \\
0.0991 \\
(0.0502)\end{array}$ & $\begin{array}{r}\text { SER } \\
0.0432\end{array}$ & $\begin{array}{l}\text { AIC } \\
-438\end{array}$ \\
\hline Fort Lauderdale & $\begin{array}{r}\theta_{12} \\
0.6268 \\
(0.0841)\end{array}$ & $\begin{array}{r}\phi_{1} \\
-0.6975 \\
(0.0919)\end{array}$ & $\begin{array}{r}\phi_{2} \\
-0.3096 \\
(0.0896)\end{array}$ & $\begin{array}{r}\omega_{1} \\
0.1592 \\
(0.0218)\end{array}$ & $\begin{array}{r}\delta \\
0.8646 \\
(0.0571)\end{array}$ & $\begin{array}{r}\omega_{0} \\
-0.0320 \\
(0.0243)\end{array}$ & & 0.0275 & -557 \\
\hline Monroe & $\begin{array}{r}\theta_{12} \\
0.5907 \\
(0.0802)\end{array}$ & $\begin{array}{r}\phi_{1} \\
-0.6887 \\
(0.0877)\end{array}$ & $\begin{array}{r}\phi_{2} \\
-0.3896 \\
(0.0875)\end{array}$ & $\begin{array}{r}\omega_{1} \\
0.0610 \\
(0.0331)\end{array}$ & $\begin{array}{r}\delta \\
0.9635 \\
(0.1348)\end{array}$ & $\begin{array}{r}\omega_{0} \\
-0.0714 \\
(0.0379)\end{array}$ & & 0.0426 & -443 \\
\hline aples & $\begin{array}{r}\theta_{1} \\
0.7185 \\
(0.0594)\end{array}$ & $\begin{array}{r}\phi_{12} \\
0.2035 \\
(0.0718)\end{array}$ & $\begin{array}{r}\phi_{12} \\
-0.2481 \\
(0.1203)\end{array}$ & $\begin{array}{r}\omega_{1} \\
0.1175 \\
(0.0377)\end{array}$ & $\begin{array}{r}\delta \\
0.7003 \\
(0.1729)\end{array}$ & $\begin{array}{r}\omega_{0} \\
0.0934 \\
(0.0390)\end{array}$ & & 0.0489 & -407 \\
\hline $\begin{array}{l}\text { est of } \\
\text { South Florida }\end{array}$ & $\begin{array}{r}\theta_{12} \\
0.5763 \\
(0.0849)\end{array}$ & $\begin{array}{r}\phi_{1} \\
-0.7552 \\
(0.0875)\end{array}$ & $\begin{array}{r}\phi_{2} \\
-0.3974 \\
(0.0882)\end{array}$ & $\begin{array}{r}\omega_{1} \\
0.0527 \\
(0.0203)\end{array}$ & $\begin{array}{r}\delta \\
0.6095 \\
(0.2903)\end{array}$ & $\begin{array}{r}\omega_{0} \\
-0.0011 \\
(0.0233)\end{array}$ & & 0.0270 & -562 \\
\hline Rest of State & $\begin{array}{r}\theta_{12} \\
0.6842 \\
(0.0762)\end{array}$ & $\begin{array}{r}\phi_{1} \\
-0.6800 \\
(0.0945)\end{array}$ & $\begin{array}{r}\phi_{2} \\
-0.2226 \\
(0.0966)\end{array}$ & $\begin{array}{r}\omega_{1} \\
-0.0062 \\
(0.0212)\end{array}$ & $\begin{array}{r}-0.6742 \\
(1.5901)\end{array}$ & & & 0.0293 & -542 \\
\hline Florida & $\begin{array}{r}\theta_{12} \\
0.6326 \\
(0.0818)\end{array}$ & $\begin{array}{r}\phi_{1} \\
-0.6449 \\
(0.0951)\end{array}$ & $\begin{array}{r}\phi_{2} \\
-0.2963 \\
(0.0947)\end{array}$ & $\begin{array}{r}\omega_{1} \\
0.0581 \\
(0.0211)\end{array}$ & $\begin{array}{r}\delta \\
0.5258 \\
(0.5270)\end{array}$ & $\begin{array}{r}\omega_{0} \\
-0.0139 \\
(0.0226)\end{array}$ & $\begin{array}{r}\omega_{2} \\
0.0392 \\
(0.0371)\end{array}$ & 0.0243 & -589 \\
\hline $\begin{array}{l}\text { AIC = Akai } \\
\text { SER = Stan } \\
\text { Approxima } \\
\text { The sample }\end{array}$ & dard & Dif & on & ing & & & & & \\
\hline
\end{tabular}

lowed by Naples (.70) and the Rest of South Florida (.61). For the Rest of the State the estimate is negative, which is economically meaningless.

There is also a very clear spatial pattern to the estimated recovery. It is highest in Miami (which coincidentally is part of the CMSA at the top of Floridas urban hierarchy) and falls as one proceeds either south to the Florida Keys (Monroe County), north along I-95 to Fort Lauderdale, or northwest along I-75 to Naples. A small recovery response was also detected in the balance of south Florida (Figure 1).

Florida. Table 2 also presents estimates for a statewide regression. The fit is quite poor; only the estimate of $\omega_{1}$ is statistically significant. At first blush these results may seem paradoxical; we found a large and significant recovery impact in Miami and Fort Lauderdale and smaller significant impacts in Monroe, Naples, and the Rest of South Florida. Yet, we also found no significant statewide or Rest 
of the State impact. Several other researchers, including Guimaraes et al. found local but not statewide, aggregate effects in other disasters:

...We conclude that there was no measurable state fiscal impact from [Hurricane] Hugo. We do not deny that there may have been fiscal effects in hard-hit urban areas like Charleston [South Carolina] (fn. 8 p.113)

Similarly, although Guimaraes et al. found a statewide income impact in several industries, total personal income and total nonfarm jobs for the state were apparently unaffected:

... The income gains were neutral overall, despite a surge in construction, retail, and other sectors" (p.111). "Our analysis also showed that total employment in South Carolina was not affected by Hugo (p. 106).

One explanation for this apparent paradox is that the state work force was redistributed toward the disaster counties. Sales would decline in those counties which workers came from, tending to offset the increase in south Florida. This should show up as a negative estimate of $\omega_{1}$ in the rest of the state. In fact, the press did report a substantial number of workers swarming to the disaster area looking for work. But the amount of redistribution was not very large. The positive hurricane impact in eleven counties in the first year amounts to about 7 percent of what their taxable sales would have been without the hurricane. They account for almost one-half of statewide sales. Sales would have had to decline 7 percent in the Rest of the State to offset this positive impact.

As can be seen in Table 2, the estimated impact is indeed negative for the Rest of the State, but quite small, only 0.6 percent. Even that estimate is suspect, because the estimate of is negative and economically meaningless.

A better resolution of this apparent paradox depends upon recognition of the fact that if the variances of an aggregate and a component are of the same size, as is the case for taxable sales, an impact which is statistically significant for the component may be insignificant for the aggregate, especially the smaller the component is relative to the aggregate. ${ }^{2}$ Numerically, a 15 percent impact in the Miami and the Fort Lauderdale MSAs is only a 3.75 percent impact for Florida, since the two MSAs account for one-fourth of statewide taxable sales. In other words, the impact on taxable sales of spending insurance and transfer payments was within the normal variation of the data at the state level, but significantly outside normal variation at the MSA level. 
Unfortunately, intervention analysis is not capable of adjudicating between the two hypotheses. Guimaraes et al. contend that when a state economy is at full employment, job gains in construction as a consequence of a natural disaster can be at the expense of jobs in other industries. Similarly, job gains in the disaster area can be at the expense of jobs in other regions of the state. We suggest that the data are also consistent with the possibility that a state economy operates above full employment temporarily or that capacity increases (through migration, multiple job holding, and increased labor force participation) during the recovery from a natural disaster.

\section{COMPARISON TO EARLIER RESEARCH}

Our estimates of the path of recovery can be directly compared to Cochrane (1996) who also examined Hurricane Andrew, and to Chang (1983) and Cochrane (1992) who looked at other disasters.

Hurricane Andrew. Cochrane (1996) presents some "quick and dirty" estimates of the indirect impact on taxable sales in Los Angeles and Miami following the Northridge Earthquake and Hurricane Andrew. These estimates are based on the ratio of seasonally adjusted taxable sales in the disaster region relative to the rest of the state. For Los Angeles he estimates that this ratio increased 5-6 percent after the disaster, while for Miami the peak increase was 34 percent. The increase was still about 20 percent in Miami six quarters after the hurricane, judging by his Figure 8 . He finds these estimates plausible because (1) they confirm estimates of recovery impacts from simulations of similar size hypothetical disasters and (2) the ratio of the percentage increase in taxable sales in Miami to the increase in Los Angeles is similar to the ratio of the reconstruction stimuli in the two regions.

Our estimate of the peak impact in Miami is a 24 percent increase over what taxable sales would have been without the hurricane. This occurred in October 1992, the second month of the recovery. The impact 18 months later is 12 percent, and the lingering impact in year 4 is 10 percent.

We suspect that Cochrane's rather high estimate of the recovery impact in Miami is due in part to the failure of his "quick and dirty" method to account for the differential business cycle magnitudes in Miami vis-a-vis the rest of Florida. That is, real taxable sales fell 4 percent in Miami in the recessionary year of 1990 versus a mere 0.4 percent fall in the rest of Florida. Hence, Miami would be expected to experience a larger percentage increase in taxable sales than Florida simply as a matter of returning to full employment after the recession. One of the advantages of the time series models we used in our estimates is that they incor- 
porate the business cycle experience of each area of Florida separately and thus can control for this fact in the counterfactual simulation.

Hurricane Frederic. Chang (1983) found that city sales tax revenue in Mobile, Alabama, in September 1979 (the month of Hurricane Frederic touched land) fell 12 percent below his forecast of what would have occurred had there been no hurricane. Mobile tax revenue was essentially the same as forecast in the subsequent month (October), and 28 percent above forecast in November, the second month of the recovery. (The recovery impact in November compares with a 24 percent Christmas surge in his "no-hurricane" forecast.) Coincidentally, these are very close to the 12 percent initial decline and 24 percent peak rise two months later that we measured for Miami sales. On the other hand, Chang found that the impact in Mobile did not persist as long as we found for Miami. His compound rate of decline from November to July was .75. By August 1980, he estimates that the recovery impact had declined to zero.

Hurricane Hugo. In his analysis of the recovery from Hurricane Hugo, Cochrane (1992) found that taxable sales declined 20 percent in Charleston County, South Carolina, and 30 percent in Horry County in September 1989, the month the hurricane struck. (He regressed taxable sales on a set of dummies to control for seasonality, "the region's ordinary annual growth," and the months after the disaster.) Sales rebounded strongly in Charleston the next month, but remained depressed in Horry. The peak impact occurred in November and represents about a 10 percent increase above what sales would have been without the hurricane. From November 1989 to March 1990, the rate of decline in the recovery impact on taxable sales works out to .88 per month. Although the peak spending increase in Charleston estimated by Cochrane (10 percent) is smaller than we estimated for Miami ( 24 percemt), the persistence of the transitory impact is very similar in both cases (.88 in Charleston versus .87 in Miami). However, we also estimated a long-persisting component that still lingers and which apparently is absent from Charleston.

Hurricanes are complex economic shocks, and our measurements of the direct shock and the indirect economic impacts are imprecise, since we have too few examples with which to generalize (Ellson et al. 1984, Cochrane 1996), but as the example of business cycle analysis shows, eventually the set can become large enough so that generalizations can be made (Zarnowitz 1985). At this point, the best we can do is document the range of experience. In the cases studied, insured losses ranged from 32 percent to 102 percent of annual personal income. The immediate decline in taxable sales ranged from 12-30 percent, while the peak recovery surge ranged from 10-34 percent. Two of the disasters occurred near a business cycle peak, while Hurricane Andrew occurred as the economy was recovering from a trough. 
TABLE 3

Estimated impact of Hurricane Andrew on real taxable sales in Florida

\begin{tabular}{|c|c|c|c|c|c|c|c|}
\hline & $\begin{array}{l}\text { Aug. } \\
1992\end{array}$ & $\begin{array}{l}\text { Sept. } \\
1992 \\
\end{array}$ & year 1 & year 2 & year 3 & year $4 *$ & total** \\
\hline Miami & -0.161 & 0.206 & 2.767 & 2.125 & 1.857 & 0.768 & 7.517 \\
\hline Ft. Lauderdale & -0.033 & 0.173 & 1.053 & 0.200 & 0.008 & -0.010 & 1.252 \\
\hline Monroe & -0.006 & 0.005 & 0.051 & 0.041 & 0.027 & 0.008 & 0.128 \\
\hline Naples & 0.014 & 0.017 & 0.089 & 0.015 & 0.022 & 0.011 & 0.138 \\
\hline Rest of South Florida & -0.002 & 0.087 & 0.238 & -0.014 & -0.024 & -0.011 & 0.189 \\
\hline Sum & -0.188 & 0.487 & 4.198 & 2.369 & 1.891 & 0.766 & 9.224 \\
\hline
\end{tabular}

\section{ESTIMATED TOTAL IMPACT}

In their analysis of Hurricane Andrew in Florida, Bolton and Kimbell (1995) ask, "Why didn't we see more spending in Florida?" Using an informal approach, they estimate a spending impact of $\$ 6.2$ billion in the first fourteen months after the disaster, compared to their estimate of $\$ 21$ billion of insurance and governmental aid.

Having estimated a set of regressions which account for the impact of Hurricane Andrew on taxable sales, we can also ask whether the spending response is consistent with the level of outside aid received. Estimates are provided in Table 3 for several periods. To get these cumulative impacts, the equations presented in Table 2 were simulated over the period August 1992 to December 1995. The simulated values represent a "with-hurricane scenario." They were compared to simulated values from equations with identical noise parameters but lacking the intervention terms. This is the "without-hurricane" scenario. The difference between the two scenarios (adjusted for inflation) is the hurricane impact reported in Table 3.

The immediate impact in August 1992 reduced taxable sales by $\$ 188$ million from what they would otherwise have been. The biggest impact, of course, was in Miami (a loss of \$161 million), but sales also fell \$33 million in Fort Lauderdale, and \$6 million in Monroe. As the recovery began in September, sales surged \$487 million, with the largest gains in Miami and Fort Lauderdale.

The table also shows the cumulative impact over twelve-month periods (August through July). Not only is the impact the largest in Miami, it also quite persistent there. The emergency transitory component seems to have exhausted itself; the remaining impact is largely due to the long-persisting transitory term. For 
the first five months of year 4 , the impact is still about $\$ 768$ million or $\$ 1.8$ billion at an annual rate. This is about the same as the $\$ 1.9$ billion impact in year 3 .

In contrast, the impact in the Rest of South Florida is over, having lasted only 12 months. In Fort Lauderdale the recovery seems to have boosted taxable sales in the first 24 months but they have now returned to what they would have been without the hurricane. Similarly, the impact in Monroe and Naples seems to have already dissipated.

The total impact so far is $\$ 9.2$ billion. ${ }^{3}$ How long the response will continue in Miami cannot be answered until more data are accumulated.

Our answer to Bolton and Kimbell's question which began this section is twofold. First, we did see more spending in Florida-about 50 percent more, but still not as much as the amount of direct insurance and federal aid received. After an initial surge, however, recovery spending is now proceeding at a slow and steady pace and has not yet exhausted itself. Furthermore, it is very difficult to see this impact in aggregate state data; it is necessary to look at substate data.

Second, we estimate the injection of outside money to be far less $-\$ 16.0$ billion of insurance benefits plus $\$ 2.6$ billion of federal aid. ${ }^{4}$ This must be adjusted for the fact that only a portion of the construction and repair expenditure is on taxable materials and for population dispersal outside the state and for the sales tax itself. Thus the direct impact of taxable sales (before the muliplier process kicks in) is probably closer to $\$ 11.7$ billion.

Although the discrepancy between the direct impact of $\$ 11.7$ billion and the total impact, so far, of $\$ 9.2$ billion, has been narrowed, a residual still remains.

\section{CONCLUSIONS}

This paper is an exercise in measuring the indirect economic impact of a disaster on taxable sales, both spatially and dynamically. A surprising finding is that rather than a large, quick and temporary recovery from the disaster, the recovery was smaller, slower, and steadier (relative to the amount of insurance and federal aid received by victims).

Earlier research on destructive hurricanes indicated recoveries lasting from 1 year (Chang 1983) to two and one half years (Guimaraes et al. 1993). Even in the case of Hurricane Andrew, there were reports in the business press that the impact from Hurricane Andrew had "fizzled" as early as April 1994 (Hersch 1994). Presumably, the expectation of a quickly completed recovery period prompted Bolton and Kimbell to question why so little spending was observed.

In contrast, we find that the impact in December 1995, three and one half years after the disaster, is still persisting at a $\$ 1.8$ billion annual rate. We specu- 
late that part of the explanation for this was the excess supply of rental housing in Miami before the hurricane, as well as bottlenecks in the supply of repair services after the hurricane. Whatever the reason, our estimate is nevertheless consistent with the findings of Kates and Pijawka (1977), whose study of a large number of major disasters worldwide indicates a reconstruction period of from two to eight years.

Though the recovery from Hurricane Andrew shows up clearly in taxable sales, the data are not rich enough to separately estimate the permanent from the long-persisting transitory components of the impact. The real cumulative impact is estimated to be $\$ 9.2$ billion through December 1995 . The spatial impact declined with distance from Miami and was felt throughout south Florida. The dynamic responses varied geographically. In Miami, there was an initial surge which subsided a bit and was replaced by a long-persisting recovery which is difficult to distinguish statistically from a permanent impact. In Fort Lauderdale, Naples and Monroe, the initial surge gradually declined to zero.

An important issue in the literature is whether natural disasters have aggregate effects, e.g., on statewide total nonfarm employment and taxable sales. Guimaraes et al. argue that there are no such effects. We suggest an alternative hypothesis consistent with the data for Hurricane Andrew in Florida, namely, that the impact at the state level was within the normal variation of state taxable sales, but significantly larger at the MSA level. This is a very unfortunate finding because the range and quality of data for states is typically much better than for MSAs and counties. One would prefer to evaluate large disasters like Hurricane Andrew with state models (West 1996).

Intervention analysis by itself cannot resolve this controversy; one must resort to a structural econometric model that can describe the regional process of recovery. Ellson, Milliman and Roberts (1984) and West and Lenze (1994) outline some of the complexities involved. However, current economic models tend to substantially overestimate recovery impacts by a factor of 10 or more (West 1996). Hence, being able to benchmark the predictions of economic models with case studies such as the present one should lead to the improvement of the models.

In the public policy arena it has been questioned whether public policy ought to be concerned with the indirect impacts of natural disasters (West 1996). Despite the uncertainty in the measurement of the size of the disaster and in prediction of the consequences, the Florida Legislature was well aware that there would be a tax windfall from the hurricane. They enacted special legislation earmarking this windfall for recovery efforts not covered by insurance or federal aid. (They anticipated a windfall of $\$ 489$ million in the first 23 months, which implies a taxable sales impact of $\$ 8.9$ billion dollars.) 
Beyond the tax impacts, public policy affects the speed of recovery as well as its magnitude. First, each level of government faces decisions about repair and replacement of its own hurricane-damaged capital stock. Second, the federal government affects the recovery through the assistance it provides individual victims and lower levels of government. Both the amount of aid provided and the speed of its disbursement are important factors in recovery. The state also provides assistance, but perhaps just as important, the state is the author of the institutional framework within which the insurance industry operates. This includes penalizing companies that are slow in processing claims and assuming the liabilities of bankrupted companies. Finally, local governments also affect the speed of recovery through their building codes, processing of permit applications, and enforcement activities.

This pervasive influence of government can markedly retard or accelerate the overall speed, extent, and cost of recovery. However, a thorough investigation of such matters is beyond the scope of this paper.

\section{ENDNOTES}

1. Most economic time series display positive autocorrelation and this is true of taxable sales, $y_{t}$. Though the estimate of $\phi_{1}$ is negative, it is the coefficient on $z_{t-1}$; using the definition of $z$ in Eq. (1) it is possible to solve for the coefficient on $y_{t-1}$. It is positive. The sign changes because of the use of both seasonal and first differencing. (Unlike other researchers who work with seasonally adjusted data, we work with unadjusted data as recommended by Pagan and Wickens (1989).

2. The standard deviation of the first difference of the logarithm of taxable sales is .118 for Fort Lauderdale, .116 for Miami, and .103 for Florida.

3. To put this impact in perspective, note that real taxable sales in the calendar year prior to the disaster were $\$ 17.6$ billion in Miami, $\$ 12.7$ billion in Fort Lauderdale, $\$ 2.0$ billion in Naples, $\$ 1.1$ billion in Monroe, $\$ 22.1$ billion in the Rest of South Florida, and $\$ 119.8$ billion in all of Florida.

4. The estimate of federal aid is from West and Lenze (1993) Appendix p. A27; the estimate of insurance benefits was revised after that paper was written. The final estimate of $\$ 16.0$ billion is from the Florida Department of Insurance, Hurricane Andrew Quarterly Report for the Quarter Ending March $31,1994$. 


\section{REFERENCES}

Blackley, Paul R. "The 1987 Stock Market Crash and New York City Employment: an Intervention-multiplier Analysis." Journal of Regional Science 32 (1992): 367-374.

Blanchard, Olivier. "Consumption and the Recession of 1990-91." American Economic Review Papers and Proceedings 83 (1993): 270-274.

Bolton, Nancy, and Larry Kimbell. "The Economic and Demographic Impact of the Northridge Earthquake." Paper presented at the Population Association of America annual meeting, San Francisco, California, April 6-8, 1995.

Box, G.E.P., and G.C. Tiao. "Intervention Analysis with Applications to Economic and Environmental Problems." Journal of the American Statistical Association 70 (1975): 70-79.

Brookshire, David S., and Michael McKee. "Indirect Loss Measurement and Computable General Equilibrium Model," In Jerome W. Milliman and Jorge A. Sanguinetti, eds. Indirect Economic Consequences of a Catastrophic Earthquake, A Study Conducted by Development Technologies, Inc. for the Federal Emergency Management Agency. pp. 267-325, 1992.

Chang, Semoon. "Disasters and Fiscal Policy: Hurricane Impact on Municipal Revenue." Urban Affairs Quarterly 18 (1983): 511-523.

Cochrane, Hal. "Assessment of Damage from Hurricane Hugo and the Loma Prieta Earthquake." Unpublished paper, 1992.

"Indirect Economic Losses." In Development of Standardized Earthquake Loss Estimation Methodology, Vol. 2. Menlo Park, California: Risk Management Solutions, Inc. (draft). 1995.

"Is Northridge a Model for Future Events? What are the Economic Consequences With and Without Insurance and Federal Assistance?" Paper presented at the conference, Analyzing Economic Impacts and Recovery from Urban Earthquakes: Issues for Policymakers, sponsored by Earthquake Engineering Research Institute and the Federal Emergency Management Agency, Pasadena, California, October 10-11, 1996.

Ellson, Richard W., Jerome W. Milliman, and R. Blaine Roberts. "Measuring the Regional Economic Effects of Earthquakes and Earthquake Predictions." Journal of Regional Science 24 (1984): 559-579.

Guimaraes, Paulo, Frank L. Hefner, and Douglas P. Woodward. "Wealth and Income Effects of Natural Disasters: An Econometric Analysis of Hurricane Hugo." Review of Regional Studies 23 (1993): 97-114.

Hersch, Valerie. "After Hurricane Andrew, its Business as Usual." Florida Trend 36 (April 1994): 47-52. 
Kates, Robert W., and David Pijawka. "From Rubble to Monument: The Pace of Reconstruction." In J. Eugene Haas, Robert W. Kates, and Martyn J. Bowden, eds. Reconstruction Following Disaster. Cambridge, Massachusetts: The MIT Press, 1977. 1-23.

Pagan, A. R., and M. R. Wickens. "A Survey of Some Recent Econometric Methods." Economic Journal 99 (1989): 962-1025.

Smith, Stanley K. "Demography of Disaster: Population Estimates after Hurricane Andrew." Paper presented at the Population Association of America annual meeting, Miami, Florida, May 4-7, 1994.

Smith, Stanley K., and Christopher McCarty. "Demographic Effects of Natural Disasters: A Case Study of Hurricane Andrew." Demography 33 (1996): 265-271.

West, Carol Taylor. "Indirect Economic Impacts of Natural Disasters: Policy Implications of Recent Research and Experience." Paper presented at the conference, Analyzing Economic Impacts and Recovery from Urban Earthquakes: Issues for Policymakers, sponsored by Earthquake Engineering Research Institute and the Federal Emergency Management Agency, Pasadena, California, October 10-11, 1996.

West, Carol T. and David G. Lenze. "Modeling Natural Disaster and Recovery: A General Framework for Developing Direct Regional Impacts and a Specific Application to the Case of Hurricane Andrew." University of Florida, Department of Economics, Working Paper 93-94-13, 1993.

West, Carol T. and David G. Lenze. "Modeling the Regional Impact of Natural Disaster and Recovery: A General Framework and an Application to Hurricane Andrew." International Regional Science Review 17 (1994): 121-50.

Zarnowitz, Victor. "Recent Work on Business Cycles in Historical Perspective: A Review of Theories and Evidence." Journal of Economic Literature 22 (1985): 523-80. 